\title{
Patients' perceptions of day surgery: a survey study in China surgery
}

\author{
WP Yu, Y Chen, GM Duan, H Hu *, HS Ma, Y Dai
}

\section{A B S T R A C T}

Objective: To investigate patients' perceptions of day surgery, specifically their convenience; social, functional and economic values; risk perceptions; and patient satisfaction.

Design: Cross-sectional questionnaire survey.

Setting: West China Hospital in Chengdu City, China.

Participants: All the day-surgery patients admitted to the Centre for Day Surgery in December 2011.

Main outcome measures: Demographic profiles, each patient's value and risk perceptions about day surgery, as well as overall satisfaction with day surgery.

Results: Convenience value and social value were emphasised by $87 \%$ and $60 \%$ of the 153 valid respondents, respectively. Comparatively speaking, functional and economic value were respectively chosen by $50 \%$ and $43 \%$ of the respondents, while $75 \%$ worried about postoperative complications and adverse events, only $53 \%$ and $27 \%$ worried about rehabilitation knowledge and psychological risks,

This article was published on 7 Oct 2013 at www.hkmj.org. respectively. More than $95 \%$ of the respondents were satisfied with the clinic service and staff attitudes, hospital surgery environment, operating skills and

results, but fewer (84\%) were satisfied with the communication processes surrounding day surgery.

Conclusion: Patients exhibited high acceptance and satisfaction regarding day surgery. The convenience experienced by patients and their families is the main perceived value of day surgery. Nevertheless, during the recovery process patients are concerned about possible adverse events, treatment of postoperative complications, and lack of information. These aspects of care delivery warrant improvement through redesign of the day surgery service.

\section{Hong Kong Med J 2014;20:134-8}

DOI: 10.12809/hkmj133966

${ }^{1}$ WP Yu, PhD

${ }^{2} Y$ Chen, MB, BS

${ }^{1} \mathrm{GM}$ Duan, $\mathrm{PhD}$

${ }^{2} \mathrm{H} \mathrm{Hu}$ *, $\mathrm{PhD}$

${ }^{3} \mathrm{HS} \mathrm{Ma}, \mathrm{MB}, \mathrm{BS}$

${ }^{3} Y$ Dai, MB, BS

Business School of Sichuan University, Chengdu, China

2 State Key Laboratory of Quality Research in Chinese Medicine, Institute of Chinese Medical Sciences, University of Macau, Taipa, Macao

${ }^{3}$ West China Hospital, Sichuan University, Chengdu, China

* Corresponding author: haohu@umac.mo

New knowledge added by this study

- Patients appreciate the convenience and social benefits of day surgery, but are worried about postoperative complications and adverse events.

Implications for clinical practice or policy

- Educations about day surgery should be provided to both health care workers and the public to enhance understanding of day surgery services.

- Hospitals should communicate with patients better during and after day surgery.

- Specific mechanisms for dealing with postoperative complications and adverse events after day surgery should be established.

\section{Introduction}

Day surgery is defined as a process in which a patient undergoes surgery and stays in the hospital for less than 24 hours. ${ }^{1}$ As an innovative form of medical practice, it is growing increasingly popular globally. ${ }^{2-4}$ For example, around $70 \%$ to $80 \%$ of North American patients expressed a preference for day surgery. ${ }^{5}$ In Scotland, among all operations the percentage involving day surgery increased 570\% from 1981 to $1995 .^{6}$ Advances in surgical technology continue to render day surgery more acceptable and suitable for minimally invasive or minor operations compared with traditional surgery, thus expanding its scope. In the past, almost all surgical patients had to stay in hospital until they were capable of caring for themselves and became ambulant, and they returned to hospital for removal of sutures. Under such circumstances, even for wound healing, patients had to stay in hospital for 21 days, which generated great social and economic pressure that patients and their families had to endure. Comparatively, many patients find day surgery to be more 'economical and reliable.7 Day surgery can provide not only economic, but also social advantages to patients. These include 
shorter hospital stays, avoiding the drawbacks of a hospital environment (cross-infection and less inconvenience to family members). ${ }^{8}$ Day surgery also benefits hospitals by increasing the quantity of successful operations, while maintaining efficient use of resources.

Many patients nevertheless worry about the uncertainties of day surgery. In addition to the uncertainty inherent in the operation itself, the more rapid day surgery model creates unique challenges for postoperative care. Many patients worry about the uncertainty of their postoperative recoveries. ${ }^{9}$ Some choose continuous rest in hospital post-surgery, thinking it better to recover under the direct supervision of doctors, which tend to counter day surgery preferences. ${ }^{10}$ For patients, these uncertainties make day surgery a controversial medical choice, despite its many advantages. ${ }^{11}$

Consequently, further exploration of patient perceptions about day surgery becomes crucial to accomplish long-term improvements and the promotion of such practice, which is particularly important where day surgery is in its infancy, such as in China. There was no day surgery in China until 2005, when hospitals in Chengdu, Shanghai, Tianjin, and elsewhere began to experiment with the concept to address the rising demand for surgery. Hospitals and doctors therefore have strong motivation to appreciate patients' perceptions of day surgery, wherever it is a fairly new medical service.

Therefore, the aim of this study was to investigate patients' perceptions of day surgeryspecifically with regard to convenience; social, functional and economic attributes; risk perceptions; and overall satisfaction.

\section{Methods}

\section{Study design and sampling}

The study was conducted using a questionnaire survey in the West China Hospital, Sichuan Province, China. This hospital was founded in 1892, and is one of the country's leading general hospitals. It is affiliated to Sichuan University, which has been selected as a national clinical and education base by the Ministry of Health, China. It has 7800 employees and 38 clinical departments providing complete medical services covering all clinical areas. Being the most highly regarded hospital in southwestern China, it copes with an ever-increasing demand for surgery, for which reason the Centre for Day Surgery was created.

This survey study was reviewed and approved by West China Hospital in advance, and involved interviews of all 225 patients admitted to the Centre in December 2011. In all, questionnaires were directly distributed to 200 patients post-surgery and collected on-site after completion by the
病人對日間手術的看法：中國的一項調查研究 余偉萍、陳瑩、段桂敏、胡豪、馬洪升、戴艷

目的：探討病人對日間手術（即非住院手術）的看法, 特別是在便 利、社會、功能和經濟價值方面, 以及風險認知和病人滿意度方面。

設計：橫斷面問卷調查。

安排：中國四川省成都市四川大學華西醫院。

參與者：2011年12月所有於日間手術中心接受手術的病人。

主要結果測量 : 人口學資料、每位病人對日間手術的看法和風險認知 和整體滿意度。

結果：153名受訪者中，87\%着重日間手術的便利，60\%則着重其 社會價值。相對而言, 只有 $50 \%$ 和 $43 \%$ 分別着重其功能和經濟價 值。 $75 \%$ 受訪者擔心術後併發症及不良反應, 另 $53 \%$ 擔心復康知識不 足, 只有 $27 \%$ 有心理風險。95\%以上的受訪者對診所服務和員工態 度、醫院的手術環境、操作技能和手術結果感到滿意, 相對較少受訪 者 $(84 \%)$ 對於有關日間手術的溝通過程感到滿意。

結論：病人對日間手術的接受程度高, 且滿意度較高。病人及家屬認 為日間手術的主要價值在於便利。然而, 病人在復康過程中會擔心可 能出現的不良反應、術後併發症的治療和缺乏醫護知識。透過重新設 計的日間手術服務, 這些方面的護理有待改善。

adult patients themselves or the family members of patients younger than 16 years old. In addition, telephone survey was conducted for another 25 patients who had left hospital at once after the surgery. The telephone survey questionnaires were conducted verbally and completed by the researcher. Informed consent was obtained from all patients and/or carers before the questionnaire was used.

\section{Measurement}

The questionnaire comprised four parts. The first collected background information including the patient's gender, age, residence location, and surgery type. The second explored each patient's perceptions about day surgery, including: (1) convenience (defined as shorter in-patient and treatment duration); (2) social value, in terms of reducing its impact on the lives of family members; (3) functional value (receipt of safer and more effective treatment); and (4) economic value, defined as saving in expenses by patient and carers (from loss of earnings and travel by patient and carers). The third part evaluated the patient's perceptions of day surgery, in terms of: (1) risk of postoperative complications and adverse events, not amenable to timely treatment after returning home; (2) uncertainty about the risks of the rehabilitation process (defined as insufficient medical knowledge about rehabilitation in the absence of medical care); and (3) psychological risk, described in terms of insufficient psychological preparation for recovery in the absence of medical care. The 
fourth part explored the patient's satisfaction with day surgery, including the clinical service, attitude of staff, hospital surgery environment, operating skills, operation results, and communication with the patient. In the last three parts, the patients were asked to choose "Yes" or "No" answers.

\section{Data analysis}

We used the Statistical Package for the Social Sciences (Windows version 19.0; SPSS Inc, Chicago [IL], US) for the statistical analysis. All the continuous variables were presented as means and standard deviations (SDs). Categorical variables were presented as frequencies and percentages. Fisher's exact test was applied to compare the different value perceptions according to surgery types. A two-

TABLE I. Patient demographic profiles $(n=153)$

\begin{tabular}{|lc|}
\hline Characteristic & No. (\%) of patients \\
\hline Gender & $70(46)$ \\
\hline Male & $83(54)$ \\
\hline Female & \\
\hline Age-group (year) & $16(10)$ \\
\hline$<10$ & $9(6)$ \\
\hline $10-19$ & $18(12)$ \\
\hline $20-29$ & $35(23)$ \\
\hline $30-39$ & $33(22)$ \\
\hline $40-49$ & $17(11)$ \\
\hline $50-59$ & $18(12)$ \\
\hline $60-69$ & $7(5)$ \\
\hline$\geq 70$ & \\
\hline Surgery type & $78(51)$ \\
\hline General surgery & $50(33)$ \\
\hline Gynaecology & $21(14)$ \\
\hline Ear, nose, throat and eye & $4(3)$ \\
\hline Other & $103(67)$ \\
\hline Residence & $50(33)$ \\
\hline Chengdu City & \\
\hline Other cities in Sichuan Province & \\
\hline
\end{tabular}

tailed $\mathrm{P}$ value of $<0.05$ was considered statistically significant.

\section{Results}

\section{General sample information}

From the 225 questionnaires, those with incomplete answers were removed. Finally 153 valid questionnaires were obtained, giving a completion rate of $68 \%$. The background information about these 153 patients (70 males and 83 females) is summarised in Table 1 . The mean age of the patients was 39 (SD, 20) years. In all, $67 \%$ of the patients came from Chengdu City and the others were from other cities in Sichuan Province. More than half of the patients underwent general surgery; $63 \%$ of them already knew about day surgery to some extent before hospitalisation for their surgery.

\section{Perceptions about the value of day surgery}

As shown in Table 2, the convenience value related to shorter in-patient stays and treatment duration was the most emphasised (87\%). The social value of reducing the influence of surgery on the lives of the patients and their family members was chosen by $60 \%$ of the respondents. Comparatively, the functional value for patients receiving safer and more effective treatment and the greater economic value (reducing expenditure on surgery) was chosen by $50 \%$ and $43 \%$ of the respondents, respectively.

Table 2 also shows the numbers of patients having "Yes" or "No" responses for each type of surgery and for different perception categories. It illustrates that respondents undergoing different types of day surgery had significantly varied perceptions about its convenience, but there were no significant differences in terms of social, functional, or economic perceptions.

\section{Risk perceptions of day surgery}

Regarding patient perceptions about the risks of day surgery, most $(75 \%)$ worried that they would not receive timely treatment if they were to experience a sudden postoperative complication or adverse event

TABLE 2. Value perceptions associated with different types of day surgery

\begin{tabular}{|c|c|c|c|c|c|c|c|c|}
\hline \multirow[t]{3}{*}{ Surgery type } & \multicolumn{8}{|c|}{ No. (\%) of patients } \\
\hline & \multicolumn{2}{|c|}{ Convenience valued } & \multicolumn{2}{|c|}{ Social aspects valued } & \multicolumn{2}{|c|}{ Functional aspects valued } & \multicolumn{2}{|c|}{ Economic aspects valued } \\
\hline & Yes & No & Yes & No & Yes & No & Yes & No \\
\hline General surgery & $64(82)$ & $14(18)$ & $49(63)$ & $29(37)$ & $35(45)$ & $43(55)$ & $33(42)$ & $45(58)$ \\
\hline Gynaecology & $47(94)$ & $3(6)$ & $32(64)$ & $18(36)$ & $28(56)$ & $22(44)$ & $22(44)$ & $28(56)$ \\
\hline Ear, nose, throat and eye & $20(95)$ & $1(5)$ & $9(43)$ & $12(57)$ & $12(57)$ & $9(43)$ & $10(48)$ & $11(52)$ \\
\hline Other & $2(50)$ & $2(50)$ & $2(50)$ & $2(50)$ & $1(25)$ & $3(75)$ & $1(25)$ & $3(75)$ \\
\hline$P$ value & 0.025 & - & 0.324 & - & 0.405 & - & 0.880 & - \\
\hline Total & $133(87)$ & $20(13)$ & $92(60)$ & $61(40)$ & $76(50)$ & $77(50)$ & $66(43)$ & $87(57)$ \\
\hline
\end{tabular}


after discharge. About half of the respondents were concerned about rehabilitation knowledge that was inherent in the absence of medical professionals to provide specific advice during recovery. This shortfall of medical knowledge could inhibit and lengthen the recovery period. In contrast, only $27 \%$ of the respondents considered there was significant psychological risk from day surgery (Table 3 ). There was no significant difference among the different surgery types with respect to risk perceptions.

\section{Patient satisfaction with day surgery}

Table 4 reveals that the respondents were generally satisfied with day surgery. More than 95\% were satisfied with the clinic service process, service attitude of the staff, the hospital surgery environment, operating skills and the results. Fewer respondents $(84 \%)$ expressed satisfaction with the communication processes surrounding day surgery, but there was no significant difference for this parameter for the different surgery types.

\section{Discussion}

Our study indicates that day surgery (a new type of medical service in China) is being applied to patients of various ages, as shown by the wide distribution of patient age-groups. Minimally invasive operations, particularly general and gynaecological surgeries, were the main types. Day surgery was embraced not only by patients from that city but also those from other cities. This implies patients' appreciation for efficiency of day surgery.

The efficiency that day surgery delivered to patients was considerable convenience, which was highly valued. Patients think day surgery can save

TABLE 3. Patients' risk perceptions about day surgery $(n=153)$

\begin{tabular}{lc}
\hline Risk perception & No. (\%) of patients \\
\hline $\begin{array}{l}\text { Risk of postoperative complications } \\
\text { and adverse events }\end{array}$ & $114(75)$ \\
Lack of rehabilitation knowledge & $81(53)$ \\
Psychological risk & $42(27)$ \\
\hline
\end{tabular}

TABLE 4. Patient satisfaction with day surgery

\begin{tabular}{lc}
\hline Aspect of satisfaction & No. (\%) of patients \\
\hline Clinic service process & $150(98)$ \\
Service attitude & $152(99)$ \\
Environment on wards & $152(99)$ \\
Operating skill & $152(99)$ \\
Operation result & $146(95)$ \\
Communication process & $129(84)$ \\
\hline
\end{tabular}

them from having to spend time in hospital, and decrease interruptions to their normal lives. Patients who underwent ear, nose and throat surgery, eye surgery, and gynaecological surgery placed significant emphasis on the convenience of day surgery. Moreover, the social value was emphasised, in that day surgery required less additional care by family members. Patients paid much less attention to functional and economic aspects, which suggests that while patients were confident about the quality of day surgery, its monetary burden was not a major determinant for them. Convenience for patients and their families was the main reason they choose day surgery, which implies that hospital should promote and emphasise this aspect.

Although our study acknowledges the value of day surgery, it nevertheless reveals that patients are conscious of and concerned about its potential risks. Risk of postoperative complications and adverse events posed a particular concern, more so than lack of rehabilitation knowledge and any psychological risks. Because patients must be discharged soon after surgery, they worry about unexpected postoperative complications or adverse events, where they might not be able to receive timely appropriate treatment, unlike the situation for in-patient recovery. In addition, the patients were concerned about whether they would experience smooth rehabilitation at home, without recourse to professional medical and psychological consultation opportunities with doctors or nurses.

Patient satisfaction is an important indicator for assessing improvements in medical service. ${ }^{12}$ The patients in this study generally exhibited high degree of satisfaction with day surgery, which is consistent with findings in the literature. ${ }^{13}$ While most were satisfied with the clinical service process, service attitude, the hospital surgery environment, and operating skills and results, some expressed dissatisfaction with the levels of communication. They complained that hospital staff lacked requisite communication skills to put patients and their family members at ease, resulting in pre- and postsurgery anxiety. Despite time constraints, in the context of day surgery, sufficient communication and interaction between patients and hospital staff is very important.

Both patients and health care workers very likely have concerns and uncertainties regarding the change from usual in-patient surgery to day surgery. Therefore, it is important to provide education to health care workers as well as the public to enhance their understanding of day surgery as a new medical service. Specifically, hospitals should enhance communications between doctors and day surgery patients, pre- and post-surgery, to increase understanding of what it involves, so as to decrease their concerns about risks and facilitate 
recovery. Specific training and reference materials about possible post-surgery complications and other problems could be provided to patients and their family members. Hospitals can also establish telephone consulting services to patients who have undergone day surgery to deal with enquiries about the recovery process. Moreover, specific mechanisms should be established to address possible recovery accidents, providing patients with rapid access to inpatient medical treatment rather than ordinary outpatient services.

Regarding the limitations of this study, it focused only on patients who had undergone day surgery in December 2011, which may only reflect information about day surgery during its development stages. Nevertheless, patients' perceptions of day surgery remain a potential topic for further investigation. Additional research in more hospitals could provide a more comprehensive understanding of day surgery as a new medical practice. We studied day surgery patients from West China Hospital, but given that day surgery practice may be significantly diversified, replication of this study elsewhere could provide more diverse insights. Second, future study could investigate doctors' perceptions of day surgery. As key operators of the day surgery model, they are crucial to its success and their opinions and suggestions have not been systematically addressed in the literature. Future studies could target this gap to enrich the understanding of day surgery from both sides (doctors and patients). Third, comparative studies addressing patients who refuse day surgery are also necessary. These types of initiatives could provide more useful information about how to improve the practice of day surgery so as to increase patient acceptance and outcomes.

\section{Conclusion}

This study showed that the majority of patients studied accepted day surgery as an innovative medical service that offers significant convenience and social value. Main patient concerns were postoperative complications and adverse events and the lack of adequate communication with doctors and nurses about their surgery and recovery process. More convenient and comprehensive design of day surgery programmes may help to promote day surgery for more patients.

\section{Acknowledgements}

This research is supported by the key special project of Central University basic scientific research expenses (Philosophy and Social Sciences) of Sichuan University (No.skqy201208) "Hospital outpatient service quality evaluation and optimization strategy based on the patients' satisfaction" and the key project of NSFC "Resource dispatching and optimizing research in medical service (No.71131006)".

\section{References}

1. Otte DI. Patients' perspectives and experiences of day case surgery. J Adv Nurs 1996;23:1228-37.

2. Sanares-Ousley D, Bernier M, Newhouse P. Actual versus valued preoperative teaching before day surgery: patient's perspective. AORN J 1999;69:1133-4.

3. Markovic M, Bandyopadhyay M, Manderson L, et al. Day surgery in Australia: qualitative research report. J Sociol 2004;40:74-84.

4. Ojo EO. Day case surgery and developing countries: a review. Niger J Clin Pract 2010;13:459-66.

5. Jenkins K, Grady D, Wong J, Correa R, Armanious S, Chung F. Post-operative recovery: day surgery patients' preferences. Br J Anaesth 2001;86:272-4.

6. Bain J, Kelly H, Snadden D, Staines H. Day surgery in Scotland: patient satisfaction and outcomes. Qual Health Care 1999;8:86-91.

7. Davies AR, Ware JE Jr. Involving consumers in quality of care assessment. Health Aff (Millwood) 1988;7:33-48.

8. Bittmann S, Ulus H. Parent satisfaction with paediatric day-surgery: a questionnaire-based study. Ambul Surg 2004;11:3-5

9. Ojo EO, Ihezue $\mathrm{CH}$, Sule AZ, Ramyil VM, Misauno MA. The scope and utilisation of day case surgery in a developing country. East Afr Med J 2007;84:200-6.

10. Lee YC, Chen PP, Yap J, Yeo P, Chu C. Attitudes towards day-case surgery in Hong Kong Chinese patients. Hong Kong Med J 2007;13:298-303.

11. Alexander-Williams J. Arguments for day case surgery. Practitioner 1996;240:152-60.

12. Attree M. Patients' and relatives' experiences and perspectives of 'Good' and 'Not so Good' quality care. J Adv Nurs 2001;33:456-66.

13. Lemos P, Pinto A, Morais G, et al. Patient satisfaction following day surgery. J Clin Anesth 2009;21:200-5. 